\section{Reconstituted epithelial tissues and native cornea: A comparison of the influence of surfactants on ocular permeability}

\author{
Erica Zucchetti,1 Daniela Monti,1,2 \\ Patrizia Chetoni,,1,2 Silvia Tampucci,1,2 \\ Susi Burgalassi 1,2
}

1Department of Pharmacy, University of Pisa, Pisa; ${ }^{2}$ Italian Inter-University Centre for the promotion of the $3 R$ s in teaching and research, Italy

\begin{abstract}
The aim of this study was to prepare an artificial rabbit corneal epithelium (RRCE) to compare with a human corneal epithelial model and excised rabbit cornea through permeation studies to investigate differences of surfactants influence on ocular permeability of a lipophilic compound. First solubility assays with different surfactants were performed and the integrity of the RRCE was assessed by measuring transepithelial electrical resistance (TEER). The permeation parameters showed that the RRCE was more sensitive than native cornea and human cornal epithelial model to the effect of permeation enhancers.
\end{abstract}

\section{Introduction}

The purpose of this study was the evaluation of the suitability of reconstituted corneal epithelia as in vitro model for prediction of influence of different surfactants in ocular drug permeation. The tissues employed for the permeation studies were a homemade reconstituted Rabbit Corneal Epithelium (RRCE) and a human corneal epithelial model (COR-100 EpiCornealTM, MatTek), while the excised rabbit cornea was taken for comparison. For the permeations studies an experimental lipophilic compound (MAGL17b) with potential antiglaucoma activity was employed.

\section{Materials and Methods}

Tween ${ }^{\circledR} 20$, Triton ${ }^{\circledR}$ X-100, Tween ${ }^{\circledR} 80$ (T80) (Mark, Germany), Kolliphor ${ }^{\circledR}$ P188, Kolliphor $^{\circledR}$ P407, Cremophor ${ }^{\circledR}$ EL (C-EL), Kolliphor $^{\circledR}$ RH40 (K-RH40) (BASF, Germany), Briij 78 (Fluka, Switzerland), MAGL17b (newly synthesized compound), Rabbit Corneal Epithelial (RCE) cell line
(ECACC, n95081046), human corneal epithelial model (COR-100 EpiCornealTM, MatTek).

First, solubility assay of MAGL17b in water added of different surfactant was done. The three better solutions and the suspension of drug without surfactants were employed to verify the drug permeability through different substrates: excised rabbit cornea, Reconstituted Rabbit Corneal Epithelium (RRCE) and COR-100. For the study, the tissues were accommodated in perfusion apparatus with a donor and receiving compartment. The samples of receiving phase withdrawn during the permeation studies were analysed with HPLC. The integrity of epithelial models was assessed by measuring the trans-epithelial electrical resistance (TEER) before and after the permeation experiments.

\section{Results}

The drug solubility in water was only 3 $\mu \mathrm{g} / \mathrm{mL}$ for this reason different surfactant: Kolliphor ( $\mathrm{P} 188, \mathrm{P} 407$ and RH-40, Tween ${ }^{\circledR} 20$ and 80 , Triton ${ }^{\circledR}$ X-100, Briij 78 and C-EL were employed to solubilize MAGL17b.

A complete solubilisation of $0.5 \mathrm{mM}$ MAGL17b $(172 \mu \mathrm{g} / \mathrm{mL})$ was obtained only with the surfactants: T80, K-RH40 and CEL. In preliminary permeation studies the formulation with K-RH40 showed a poor permeability of MAGL17b, for this reason in the subsequent studies only the formulations T80 3\%, C-EL $8 \%$ and C-EL $1 \%$ were employed. The permeation studies performed through the excised rabbit cornea showed a lower permeability of the lipophilic drug in suspension respect with the epithelial models, this can be explained to the presence of the stroma, a very hydrophilic compartment that contrast the passage of the lipophilic drug. In the permeation studies through the excised cornea all the formulations showed a similar permeability with $\mathrm{P}_{\text {app }}$ increased in presence of surfactants (Table 1). In that performed through the two epithelial models, different results with addiction of surfactants were obtained showing that RRCE is more sensitive to their
Correspondence: Erica Zucchetti, Department of Pharmacy, University of Pisa, Pisa, Italy.

E-mail: erica.zucchetti@phd.unipi.it

Key words: Rabbit Cornea; reconstituted epithelial tissues; rabbit corneal epithelial cells; permeation studies, RCE.

Conference presentation: this paper was presented at the Second Centro 3R Annual Meeting - 3Rs in Italian Universities, 2019, June 20-21, University of Genoa, Italy.

Received for publication: 28 October 2019. Accepted for publication: 11 November 2019.

This work is licensed under a Creative Commons Attribution NonCommercial 4.0 License (CC BY-NC 4.0).

CCopyright: the Author(s), 2019

Licensee PAGEPress, Italy

Biomedical Science and Engineering 2019; 3(s3):123 doi:10.4081/bse.2019.123

action: the higher concentrations of surfactant were able to alter RRCE barrier properties. Therefore, the surfactants were able to influence the permeability through the epithelial layers altering their tight junctions. In every case, a decrease of the TEER values measured before and after permeation experiments was evident indicating some degree of suffering of the epithelial tissues caused by the test conditions. However, the results have also shown that the formulation based on C-EL8\% caused a decrease of TEER in both epithelial tissues and an opacity in the excised cornea at the end of experiment indicating a higher toxicity of the surfactant at this concentration.

\section{Conclusions}

The results obtained showed that the homemade RRCE was suitable for testing some ocular permeation enhancers even if the toxic effects produced to the higher concentrations have to be considered. Moreover, the presence of a stroma equivalent might produce a barrier closer to the native cornea.

Table 1. Permeation parameters obtained for RRCE, COR-100 and rabbit excised cornea.

\begin{tabular}{|c|c|c|c|}
\hline & \multicolumn{3}{|c|}{ APPARENT PERMEABILITY $\left(P_{a p p}\right) X 10^{2}(\mathrm{~cm} / \mathrm{h} \pm$ S.E. $)$} \\
\hline & RRCE & COR-100 & CORNEA \\
\hline T80 3\% & $8.407 \pm 0.6198$ & $0.3301 \pm 0.0038$ & $0.420 \pm 0.0655$ \\
\hline C-EL 8\% & $11.660 \pm 0.8956$ & $0.347 \pm 0.0234$ & $0.279 \pm 0.0932$ \\
\hline C-EL 1\% & $1.285 \pm 0.1694$ & $0.650 \pm 0.0174$ & $0.377 \pm 0.0081$ \\
\hline SUSPENSION & $0.351 \pm 0.0185$ & $0.190 \pm 0.0092$ & $0.083 \pm 0.0745$ \\
\hline
\end{tabular}

